\title{
XIAP is not required for human tumor cell survival in the absence of an exogenous death signal
}

\author{
John Sensintaffar ${ }^{2}$, Fiona L Scott ${ }^{1}$, Robert Peach ${ }^{1}$, Jeffrey H Hager ${ }^{2^{*}}$
}

\begin{abstract}
Background: The X-linked Inhibitor of Apoptosis (XIAP) has attracted much attention as a cancer drug target. It is the only member of the IAP family that can directly inhibit caspase activity in vitro, and it can regulate apoptosis and other biological processes through its C-terminal E3 ubiquitin ligase RING domain. However, there is controversy regarding XIAP's role in regulating tumor cell proliferation and survival under normal growth conditions in vitro.

Methods: We utilized siRNA to systematically knock down XIAP in ten human tumor cell lines and then monitored both XIAP protein levels and cell viability over time. To examine the role of XIAP in the intrinsic versus extrinsic cell death pathways, we compared the viability of XIAP depleted cells treated either with a variety of mechanistically distinct, intrinsic pathway inducing agents, or the canonical inducer of the extrinsic pathway, TNF-related apoptosis-inducing ligand (TRAIL).

Results: XIAP knockdown had no effect on the viability of six cell lines, whereas the effect in the other four was modest and transient. XIAP knockdown only sensitized tumor cells to TRAIL and not the mitochondrial pathway inducing agents.
\end{abstract}

Conclusions: These data indicate that XIAP has a more central role in regulating death receptor mediated apoptosis than it does the intrinsic pathway mediated cell death.

\section{Background}

An underlying feature of all human cancer is uncontrolled cell proliferation. However, for a tumor to increase in cell mass and malignant potential, the increase in replication rate must be accompanied by suppression of apoptosis [1]. While tumor cells can subvert many apoptotic regulators, the anti-apoptotic IAP family is thought to have a central role in this process.

There are eight IAPs in humans. All IAPs contain multiple functional domains that potentially modulate many biological processes, including apoptosis. For instance, IAPs have a role in cell-cycle regulation through mitotic spindle formation, ubiquitination of target proteins, and modulation of several signal transduction pathways [2]. Elevated IAP protein levels are

\footnotetext{
* Correspondence: jhager2@san.rr.com
${ }^{2}$ Aragon Pharmaceuticals, 4215 Sorrento Valley Blvd., Suite 215 San Diego CA

* Correspondence: jhager2@san.rr.com
${ }^{2}$ Aragon Pharmaceuticals, 4215 Sorrento Valley Blvd., Suite 215 San Diego CA 92121, USA
} 92121, USA

\section{() Biomed Central}

(c) 2010 Sensintaffar et al; licensee BioMed Central Ltd. This is an Open Access article distributed under the terms of the Creative Commons Attribution License (http://creativecommons.org/licenses/by/2.0), which permits unrestricted use, distribution, and reproduction in any medium, provided the original work is properly cited.

common in many tumor types, and a wealth of data supports their role in suppressing cell death, although the exact mechanisms by which different IAPs mediate this effect remains unclear $[3,4]$

XIAP is the most thoroughly characterized of this family, and is the only member that can directly inhibit the proteolytic activity of caspases in vitro (reviewed in Eckelmen [5]). Caspase inhibition is mediated through an 80 amino acid motif, the Baculovirus IAP Repeat domain (BIR), common to all IAPs. By contrast, cIAPs can also directly interact with caspases, but largely to target caspase degradation through the ubiquitin ligase activity of the C-terminal RING domain [6]. Importantly, XIAP inhibits caspases at both the initiation phase (caspase-9) and the execution phase (caspases-3 and 7) of apoptosis [7]. In light of these activities, XIAP inhibition through small molecules or antisense has received considerable pharmaceutical industry focus, and multiple agents have progressed to clinical trials [3]. 
A hallmark of apoptotic cell death is the presence of proteolytically cleaved, catalytically active caspases. Viable cells of many well-studied cancer cell lines have been reported to exhibit high steady-state levels of activated caspases in the absence of other markers of cell death [8]. The resistance of these cells to apoptosis is thought to be mediated, at least in part, by XIAP. If XIAP function is essential for survival of these cancer cells, then its inhibition by pharmacological or genetic targeting should increase the rate of apoptosis, without the requirement of additional exogenous signals. XIAP loss of function has been studied extensively using various genetic tools including germ line deletion [9], somatic cell deletion [10], and both transient and stable mRNA knockdown. The results have varied widely; in some reports XIAP knockdown alone resulted in decreased viability, while other studies demonstrated no effect. Mice harboring XIAP null alleles are viable and do not exhibit any overt defects in developmental or homeostatic apoptosis, aside from a slight delay in mammary alveolar development $[11,12]$. These same XIAP null mice crossed to the TRAMP mouse model of prostate cancer did not result in an alteration in tumor progression, suggesting that XIAP is not a critical regulator of tumor apoptosis in this context [13]. However, loss of XIAP function can sensitize some cell lines in vitro to apoptosis mediated by activation of either the extrinsic, caspase 8 dependent pathway, using exogenous ligands such as TRAIL $[10,14]$ and TNF $\alpha$ [15], or chemotherapeutic agents, which largely activate the intrinsic, caspase 9-dependent pathway [16-18]

Some of the different outcomes in XIAP depleted cells may be attributable to varying functional dependence on XIAP. On the other hand, there are conflicting reports even in the same cell line. In MCF-7 cells, Hu et. al., [19] reported that siRNA-mediated knockdown of XIAP had no effect on cell viability in the absence of an exogenous apoptotic stimulus. By contrast, Zhang et. al. [20] reported a 70\% decrease in MCF-7 viability within $60 \mathrm{hr}$ after transient siRNA-mediated loss of XIAP. Also, Lima et. al. [21] reported an approximately $50 \%$ decrease in viability in MCF-7 cells, 96 hr post transfection with XIAP-targeted siRNA. In another example, the effect of XIAP depletion in NCI-H460 cells ranged from approximately $20 \%$ [14] to $55 \%$ reduced viability [22]. The reported differences in phenotype upon XIAP knockdown for a given tumor cell line could be a function of degree and or duration of knockdown, the methodology for quantifying viability, or a more subtle parameter such as cell-culture conditions.

We present a systematic study of siRNA mediated knockdown of XIAP in human tumor cell lines of diverse tissue origin, including cell lines used in previous reports. In addition to assessing the effect of XIAP knockdown under normal growth conditions, we also explored whether loss of XIAP sensitizes tumor cells to either intrinsic or extrinsic inducers of cell death. Interestingly, loss of XIAP function sensitizes human tumor cell lines to TRAIL, but not inducers of the intrinsic death pathway.

\section{Methods}

\section{Cell Lines}

DU-145, HCT-116, MCF7, PC-3 and SW-620 were from the Division of Cancer Treatment and Diagnosis, National Cancer Institute (Frederick, Maryland). A-375, BxPC-3, LS 174T, and T24 were from American Type Culture Collection (Manassas, VA). PATU-I cells were from Dr. David Hockenberry at the Fred Hutchinson Cancer Research Center (Seattle, WA). All cell lines were maintained in RPMI 1640 medium (Invitrogen, Carlsbad, CA) supplemented with $10 \%$ fetal bovine serum (Invitrogen) at $37^{\circ}$ with humidified air containing $5 \% \mathrm{CO}_{2}$.

\section{siRNA Studies}

Transfections with siRNA: Silencer ${ }^{\circ}$ Select XIAP siRNAs were from Perkin Elmer Applied Biosystems (Foster City, CA). All XIAP depletions were carried out using Silencer ${ }^{\circ}$ Select siRNA ID\# s1455, except in Figure 1 where siRNA ID\# s1456 was compared to s1455. Silencer ${ }^{\circ}$ Negative Control \#1 siRNA (Perkin Elmer,\#AM4611) was included in each experiment. PLK1 siGENOME ${ }^{\circ}$ SMARTpool ${ }^{\circ}$ siRNA (Cat. No. M-003290-01-0005) and Non-targeting pool (Cat. no D-001810-10-05) were from Thermo Scientific (Waltham, MA). Cells were trypsinized, washed in medium containing serum, adjusted to $5 \times 10^{6}$ cells $/ \mathrm{mL}$ in RPMI 1640 supplemented with $10 \%$ fetal bovine serum. 2 $\times 10^{6}$ cells in a $400 \mathrm{uL}$ volume were transfected with siRNA by single pulse electroporation in a Gene Pulser ${ }^{\circ}$ Cuvette (Bio-Rad) with a $0.4 \mathrm{~cm}$ electrode gap using a Gene Pulser Xcell ${ }^{\text {mix }}$ Electroporation system (Bio-Rad, Hercules, CA) set to 230 volts, $875 \mu \mathrm{F}$.

\section{Western Blot}

Cells were lysed in modified radioimmunoprecipitation buffer (mRIPA; $10 \mathrm{mM}$ Tris, $150 \mathrm{mM} \mathrm{NaCl}, 1 \%$ (v/v) NP40, 0.5\% deoxycholate, 0.1\% SDS, 5 mM EDTA, pH 7.4) containing cOmplete protease inhibitor cocktail (Roche Applied Science, Indianapolis, IN) $48 \mathrm{hr}$ after transfection. Total protein of the clarified lysates was quantitated by Lowry Assay (Biorad DC protein assay). NuPAGE ${ }^{\bullet}$ LDS Sample Buffer and Sample Reducing Agent were added to the lysates and heated to $85^{\circ} \mathrm{C}$ for 10 mins. $20 \mu \mathrm{g}$ of total cell protein was separated in NuPAGE 4-12\% Bis Tris Gel and transferred to a nitrocellulose membrane using an iBlot $^{\oplus}$ Dry Blotting System (Invitrogen). Membranes were incubated in Blocking Buffer (LI-COR, Lincoln, NE) for 30 minutes at room temperature, followed by 60 minute incubations with mouse monoclonal antibodies against XIAP (BD Transduction Laboratories, Cat. No. 610716), 


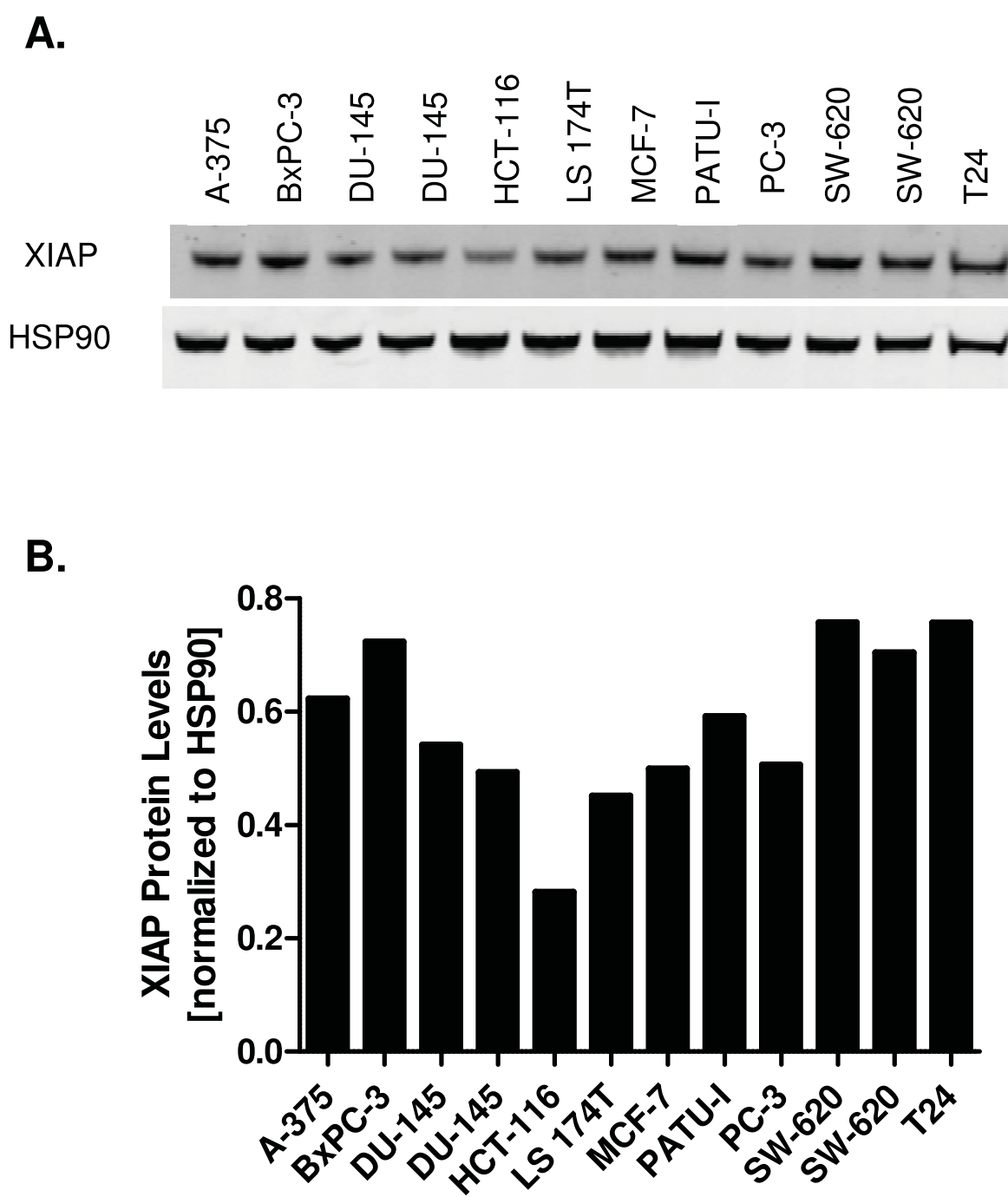

Figure 1 XIAP protein levels in a panel of human tumor cell lines. A. XIAP levels were monitored by Western blot from lysates of tumor cells. B. Quantification by LICOR Odyssey imaging. XIAP levels were normalized to the loading control HSP90 (Materials and Methods).

Hsp90 (BD Transduction Laboratories, Cat. No. 610418), or PLK1 (Cell Signaling Technology Cat. No. 208G4). Following incubation with an IRDye ${ }^{\oplus}$ Conjugated Goat Anti Mouse IgG (LI-COR), protein bands were quantified using an Odyssey ${ }^{\odot}$ Infrared Imaging System. Graphing of data to determine XIAP levels was performed using Graphpad $\mathrm{PRISM}^{\circledR}$ software. Percent XIAP levels were calculated as follows:

$\%$ XIAP $=$ (fluorescence XIAP band of sample-bkgrd/ fluorescence Hsp90 band of sample-bkgrd) $\div$ (fluorescence XIAP band of untreated cells-bkgrd/fluorescence Hsp90 of untreated cells-bkgrd)

Viability Assays

After transfection, cells were immediately diluted in RPMI 1640 supplemented with 10\% fetal bovine serum and added to clear bottom white wall 96 well plates at a concentration of 2500 cells/well in a $100 \mu \mathrm{L}$ volume.
$100 \mu \mathrm{L}$ of ATPlite ${ }^{\mathrm{TM}} 1$ step reagent was added to each well and the luminescence was measured using a Spectramax ${ }^{\oplus} \mathrm{L}$ microplate luminometer. Data was acquired using SOFTMAX ${ }^{\oplus}$ Pro software. Graphing and statistical analysis was performed using Graphpad PRISM ${ }^{\bullet}$ software. For experiments to determine TRAIL sensitivity, soluble human recombinant KillerTRAIL ${ }^{\mathrm{TM}}$ (Alexis Biochemicals, San Diego) was added at $32 \mathrm{hr}$ after transfection; cells were incubated for an additional $24 \mathrm{hr}$ prior to addition of ATPlite ${ }^{\mathrm{TM}}$.

\section{Results}

Efficient siRNA-mediated knockdown of XIAP protein levels

XIAP protein levels were monitored in 10 human tumor cell lines derived from different tumor types (Table 1 and Figure 1). The range of XIAP protein levels was 
relatively narrow, with only a 2.5 -fold difference between the highest (e.g SW-620 and BxPC3) and lowest (e.g. HCT-116) expressing cell lines. The relatively high XIAP expression in SW-620 cells was consistent with published work, where it was also shown that these cells are resistant to TRAIL mediated apoptosis [23]. Moreover, reduction of XIAP protein levels by siRNA knockdown sensitized SW-620 cells to TRAIL killing. Based on these data, we chose SW-620 cells to optimize an electroporation-based siRNA protocol for efficient knockdown of XIAP protein. The cells were electroporated with increasing concentrations of the siRNAs s1455 and s1456 (Dharmacon Inc). Decreasing XIAP protein levels were correlated with increasing concentrations of both siRNAs (Figure 2). The dose-response for each siRNA was similar and the maximum knockdown was achieved at $1 \mu \mathrm{M}$; XIAP protein levels in s1455 and s1456 treated cells were $11.5 \%$ and $12.5 \%$ of untreated controls, respectively. Since there was no significant difference between the two siRNAs, we chose s1455 for all subsequent experiments, which were all performed with $1 \mu \mathrm{M}$ of siRNA to ensure maximum knockdown. This concentration of siRNA is typical of studies that have employed electroporation $[18,24,25]$

The kinetics of XIAP knockdown was assessed over five days (Figure 3). A decrease in protein levels was evident at $24 \mathrm{hr}$, at $23 \%$ of untreated cells. A nadir of $10 \%$ was observed at $48 \mathrm{hr}$. Recovery began by $72 \mathrm{hr}$, with XIAP levels of $26 \%, 40 \%$, and $50 \%$ of controls detected at 72,96 , and $120 \mathrm{hr}$, respectively.

Effect of XIAP protein knockdown on tumor cell viability The effect of XIAP depletion on viability of the 10 human tumor cell lines was measured at various time points over $96 \mathrm{hr}$. These cell lines were either wild-type or mutant at the tumor suppressor gene, p53 (Table 1). Some reports have indicated that wild-type p53 status correlates with sensitivity to XIAP knockdown [26,27]. Cells were electroporated with $1 \mu \mathrm{M}$ XIAP siRNA s1455 or control siRNA. XIAP levels in cells treated with

Table 1 Human tumor cell lines.

\begin{tabular}{|c|c|c|}
\hline Cell Line & Cancer Type & P53 Status \\
\hline$A-375^{a}$ & Melanoma & functional \\
\hline$B \times P C-3^{b}$ & Pancreatic & mutant \\
\hline PATU-1 & Pancreatic & unknown \\
\hline DU-145 & Prostate & mutant \\
\hline$P C-3^{C}$ & Prostate & mutant \\
\hline SW- $620^{c}$ & Colon & mutant \\
\hline HCT-116 & Colon & functional \\
\hline LS 174t $T^{d}$ & Colon & functional \\
\hline MCF $^{C}$ & Breast & functional \\
\hline $\bar{T} 24^{e}$ & Bladder & mutant \\
\hline
\end{tabular}

a [42], b [43], c [44], d [45], e [46] s1455 siRNA ranged from $6 \%$ to $26 \%$ of untreated cells at $48 \mathrm{hr}$ (Figure 4A). In 6 of the 10 cell lines, there was no significant difference in viability at any time point between the XIAP depleted cells and control siRNA treated cells (Figure 4B). In the remaining 4 cell lines there was a modest, but statistically significant, 10-20\% decrease in cell viability, albeit at only one of the time points. In MCF-7 cells there was a $20 \%$ decrease in viability at $24 \mathrm{hr}$ and in PC-3 cells a $12 \%$ decrease at $72 \mathrm{hr}$. At all other time points, cell number in s1455 treated MCF-7 and PC-3 cells was equivalent to that of control siRNA treated cells. Similarly, in both LS-174T and T24 cells there was a $20 \%$ and $13 \%$ decrease in viability, at $48 \mathrm{hr}$, respectively, that was not observed at the other time points. As a positive control for siRNA mediated tumor cell death, SW620 cells were electroporated with a PLK1 siRNA $(1 \mu \mathrm{M})$. As expected for this well validated cancer target $[28,29]$ there was a $64 \%, 75 \%$ and $84 \%$ decrease in viability at 48,72 and $96 \mathrm{hr}$ post electroporation, respectively. (75\% PLK1 knockdown at 48 hr; Additional File 1). The lack of effect in the majority of the cell lines, and the modest and transient nature of the decreased viability in the other cell lines, suggests that in many tumor cell lines under normal in vitro growth conditions, XIAP has no essential role regulating proliferation or survival.

\section{XIAP depleted cells are sensitized to TRAIL but not intrinsic pathway inducing agents}

Several studies have reported XIAP depletion increases sensitivity to TRAIL mediated apoptosis [10,14,17,23,30-32]. We exposed s1455 treated cells to TRAIL to determine if XIAP knockdown was sufficient to sensitize them (Figure 5). In 6 of 10 cell lines, XIAP depletion increased sensitivity to TRAIL mediated death, indicating that the death receptor pathway is functional in those cells and that XIAP functions as a negative regulator of caspase- 8 mediated cell death. Similar results were obtained in the SW- 620 cell line with the s1456 siRNA indicating that the observed effects were not specific to siRNA s1455 (Additional File 2). Minimal or no sensitivity to TRAIL was observed in the other 4 cell lines, with or without XIAP knockdown. The lack of TRAIL mediated killing in these other cell lines may result from several possibilities, such as insufficient death receptor expression (DR4 and DR5), the glycosylaton state of these receptors or high decoy receptor expression [33,34]. In the one resistant line (DU-145) for which there is publicly available gene expression data http://dtp.nci.nih.gov/mtweb/search.jsp, the DR4/ DR5 expression is similar to the other cell lines that were also sourced from the NCI-60 panel (e.g. SW-620) and thus would appear to be sufficient to engage TRAIL mediated killing. To determine whether the degree to which XIAP knockdown sensitized cells to TRAIL was 
A.

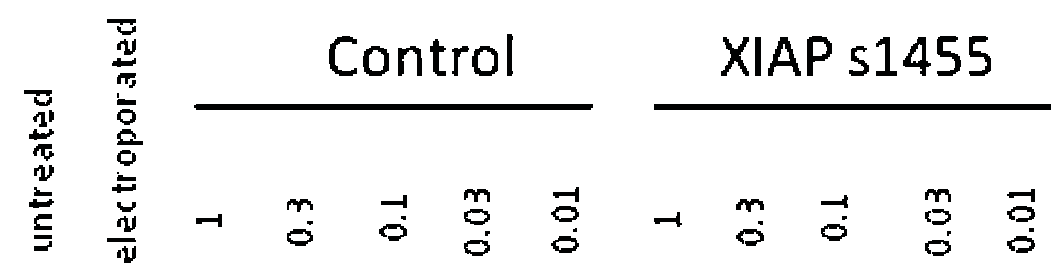

XIAP

HSP90

B.
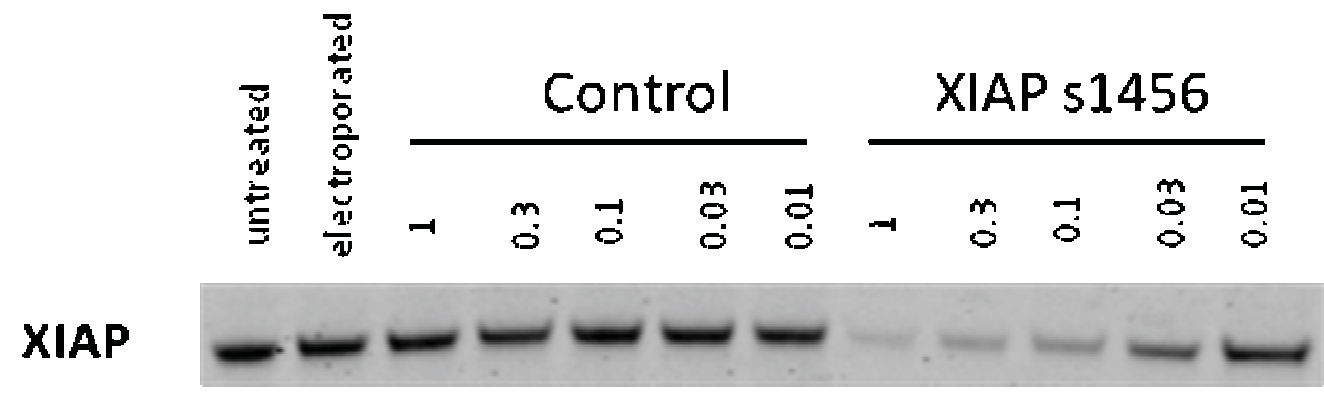

HSP90

C.
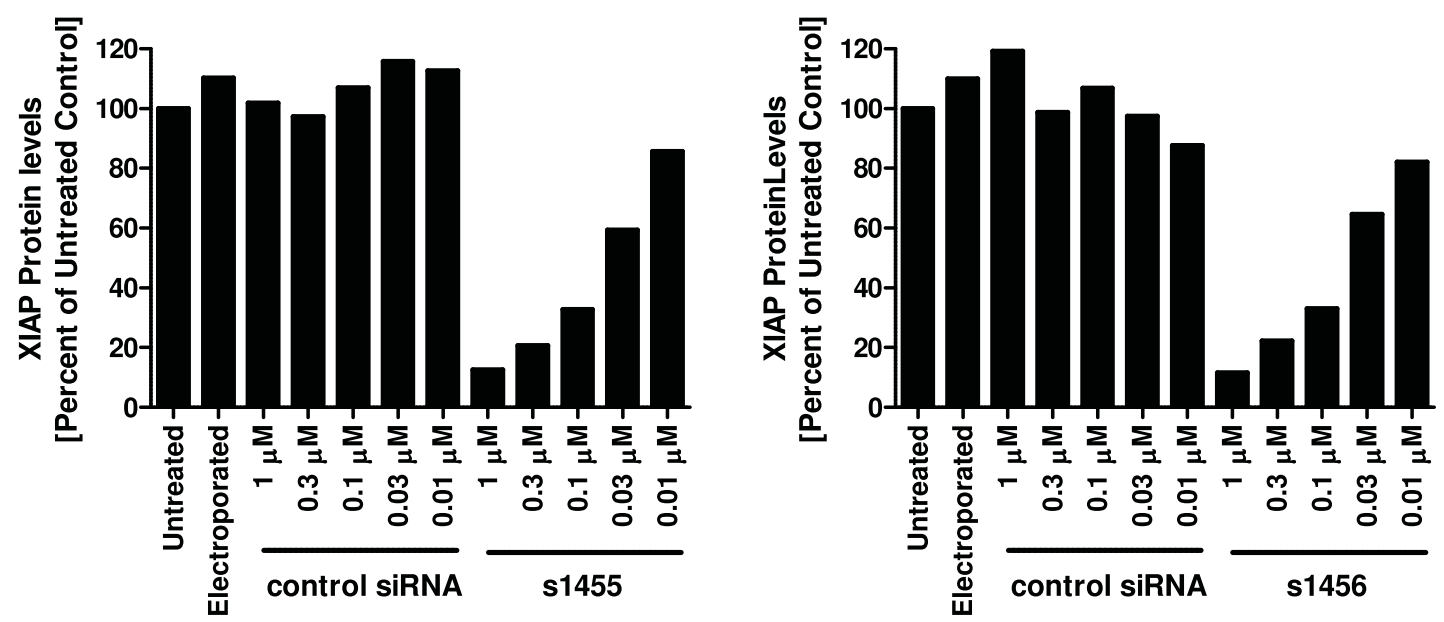

Figure 2 Dose dependent increase in XIAP knockdown with XIAP siRNA s1455 and s1456. SW620 cells were electroporated with the concentrations of siRNA indicated. After $48 \mathrm{hr}$, cells were lysed and XIAP levels were monitored by Western blot. A. s1455 B. s1456 C. Quantification by LICOR Odyssey imaging. Percent XIAP levels are expressed relative to the mean of untreated cells. 


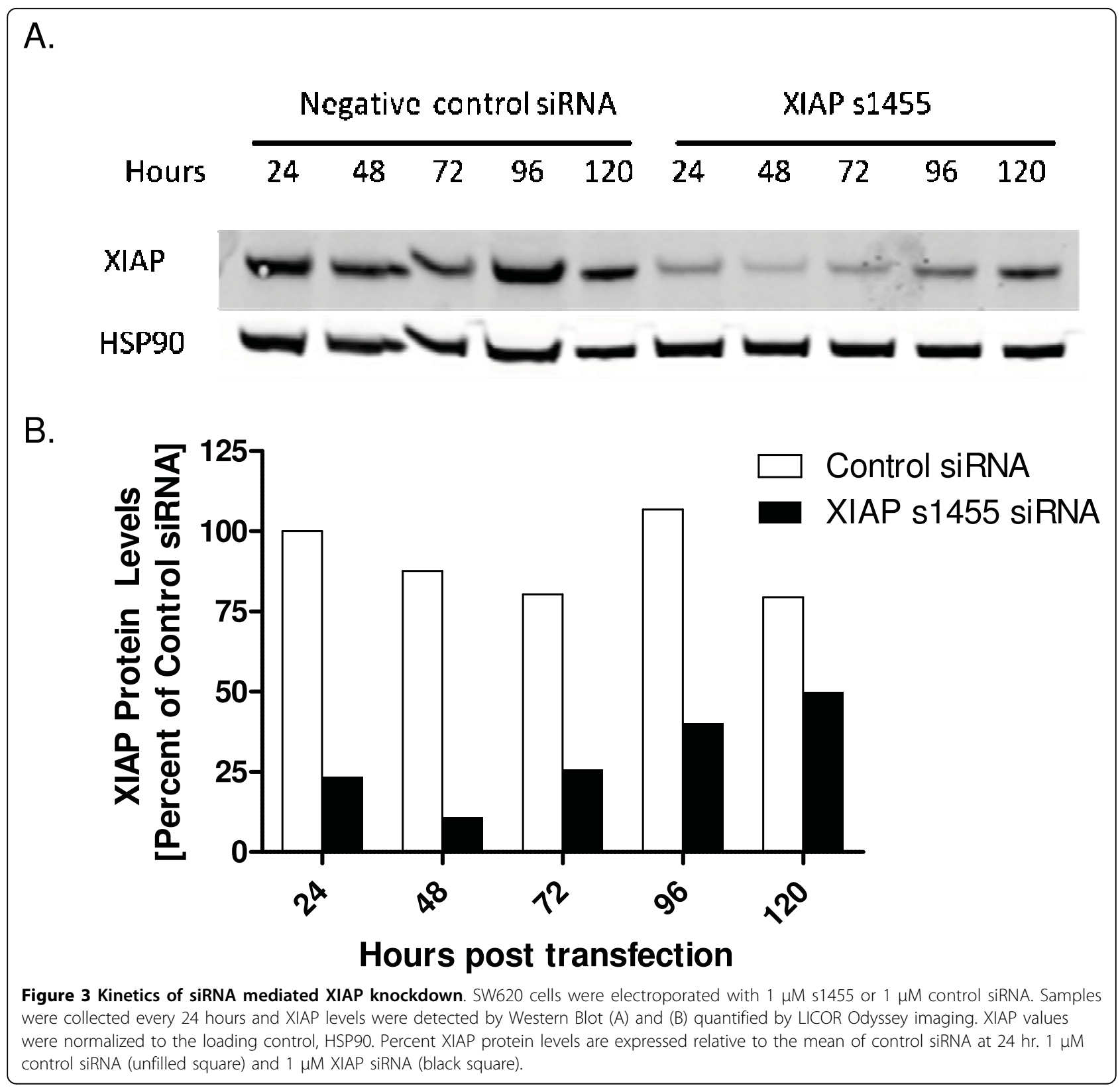

additive or synergistic in nature, we determined the viability of SW620 cells with a titration of both s1455 XIAP siRNA and TRAIL alone and in combination (Additional File 3). The Combination Index [35] indicated synergy at all 3 titrations.

To explore the role of XIAP as a negative regulator of apoptosis mediated through the intrinsic pathway, we treated XIAP-depleted HCT-116 and SW-620 cells with a variety of standard-of-care chemotherapeutics, the proteasome inhibitor bortezomib and the HDAC inhibitor SAHA. All of these agents are thought to engage the mitochondrial-based, intrinsic pathway, although by distinct mechanisms [36-39]. Twenty four hours post electroporation, cells were treated with varying concentrations of the therapeutic compounds. Cell viability was determined at both 24 and 48 hours post compound addition, thus ensuring that cells were exposed to the agents during maximal XIAP knockdown. None of the compounds significantly impacted cell viability in either cell line at $24 \mathrm{hr}$ (Figure 6A and 6C). By contrast, significant dose-dependent cytotoxicity was observed at $48 \mathrm{hr}$ for all agents (Figure 6B and 6D). In contrast to the combined effect of XIAP knockdown and TRAIL, no significant increase in cytotoxicity was observed when these agents were combined with XIAP knockdown, compared with the various control groups (Figure 6B 
A.

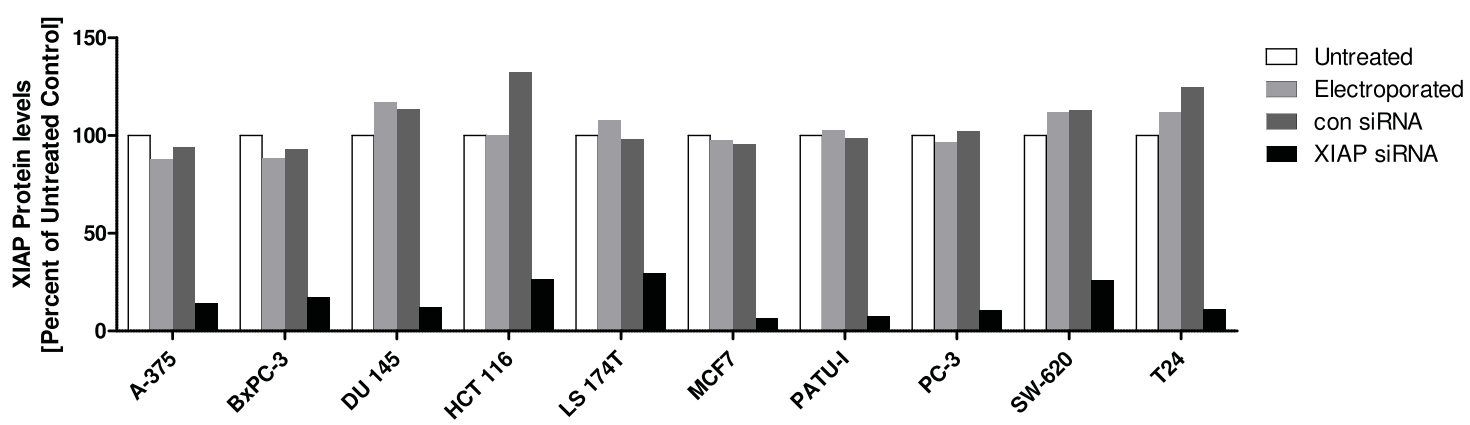

B.
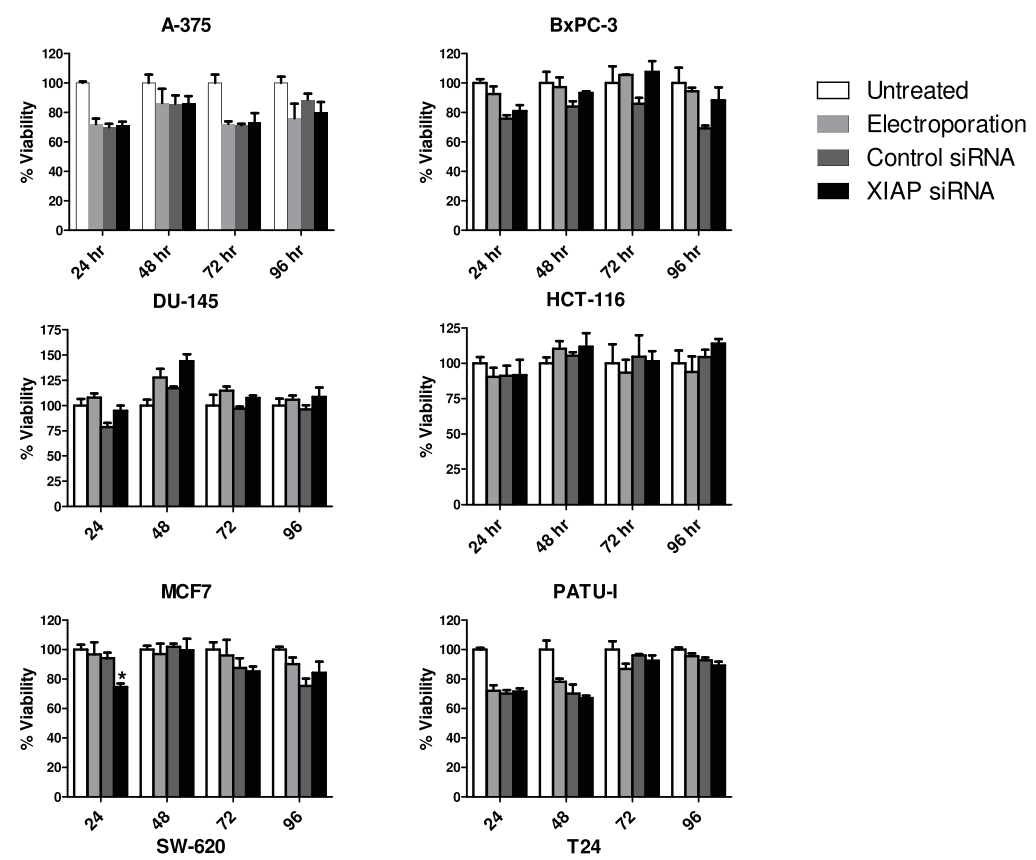

PATU-I
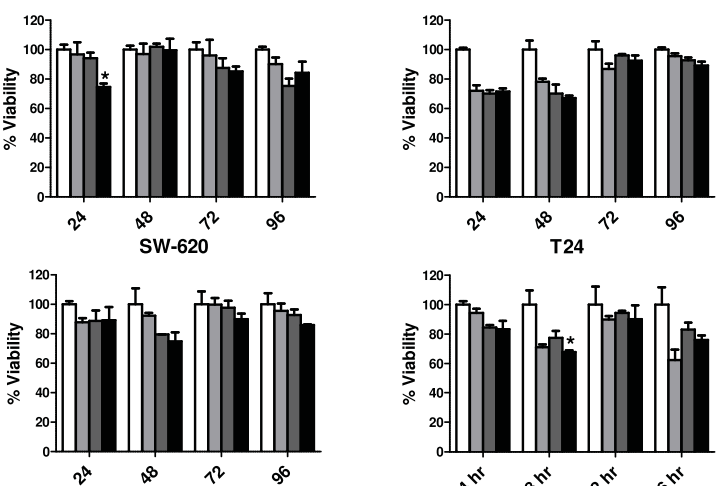

PC-3
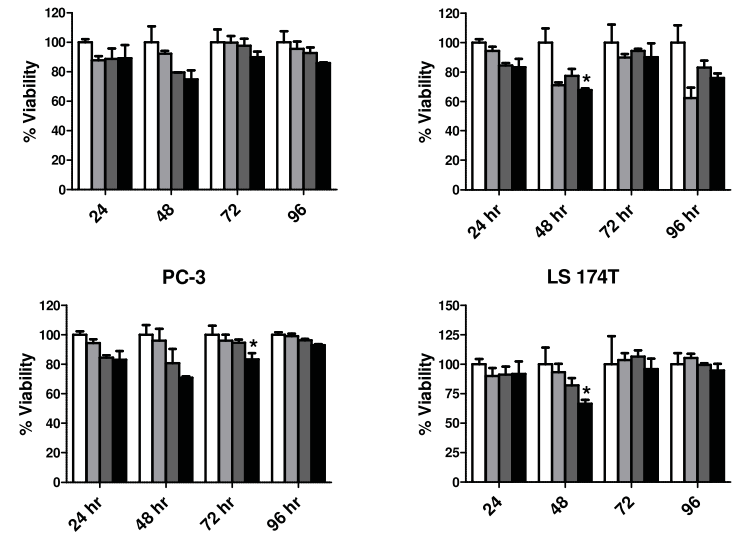

Figure 4 XIAP depletion in a panel of tumor cell lines. A. XIAP levels were monitored by Western blot from lysates of untreated cells (unfilled square), electroporated cells, (grey square), cells electroporated with $1 \mu \mathrm{M}$ control siRNA (dark grey square), or $1 \mu \mathrm{M}$ s1455 XIAP siRNA (black square) $48 \mathrm{hr}$ following electroporation. XIAP levels were quantified by LICOR Odyssey imaging. Percent XIAP levels are expressed relative to the untreated control for each cell line. B. Viablity of XIAP depleted cells was measured at 24, 48, 72 and 96 hr post electroporation; untreated cells (unfilled square), electroporated cells (light grey square), cells electroporated with $1 \mu \mathrm{M}$ control siRNA (dark grey square), or $1 \mu \mathrm{M}$ s1455 XIAP siRNA (black square). 

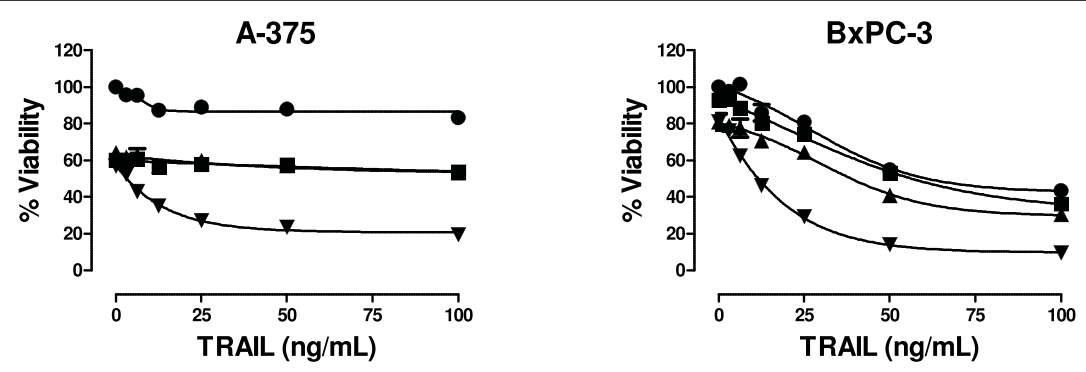

- Untreated
Electroporated

- Control siRNA

$\boldsymbol{\nabla}$ XIAP SIRNA
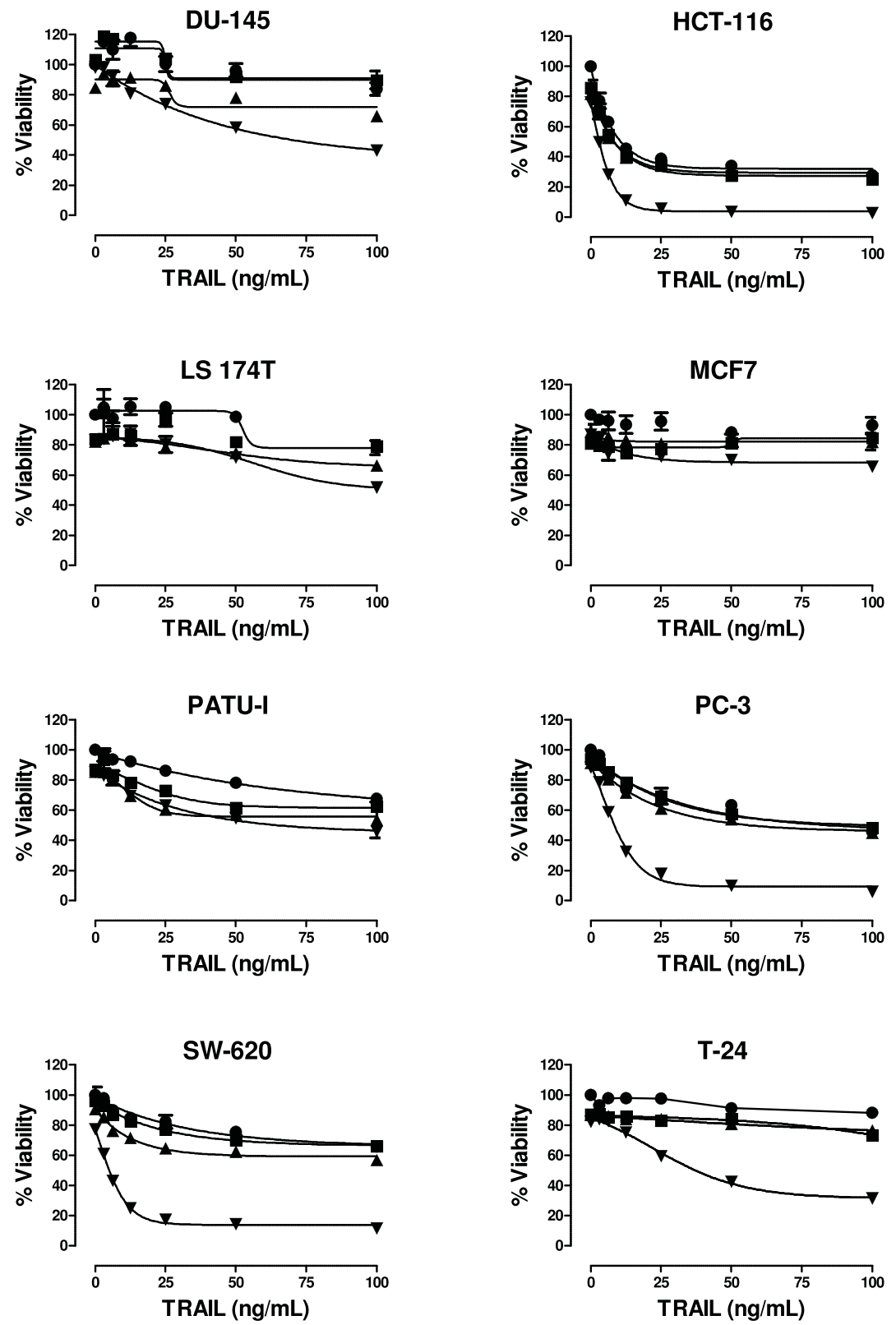

Figure 5 Effect of XIAP depletion on tumor cell viability and TRAIL sensitivity. XIAP depleted cells were exposed to TRAIL $40 \mathrm{hr}$ following electroporation, and viability was measured $24 \mathrm{hr}$ following TRAlL exposure Untreated cells (black circle); Electroporated cells (black square); 1 $\mu \mathrm{M}$ control siRNA (black triangle) $1 \mu \mathrm{M}$ XIAP siRNA (inverted black triangle). Percent viability is expressed relative to untreated controls for each cell line. A similar result was obtained with the s1456 siRNA in SW620 cells (Additional File 2). 
A.
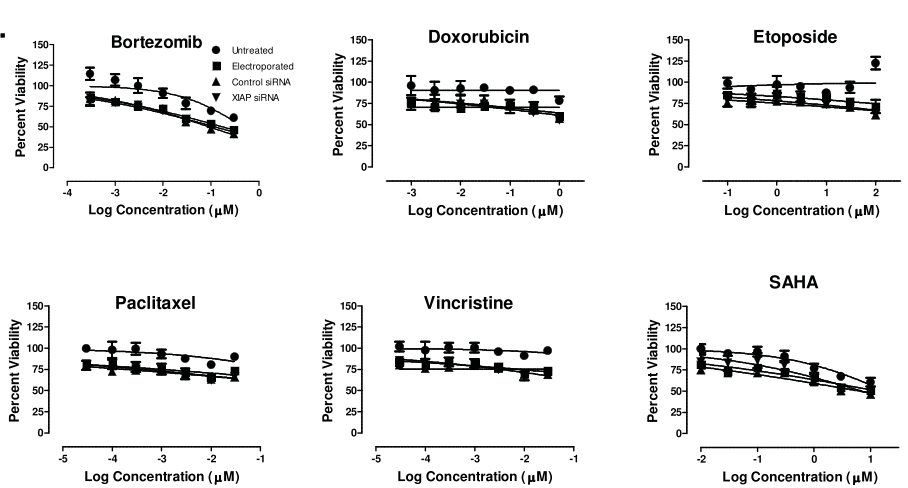

B.
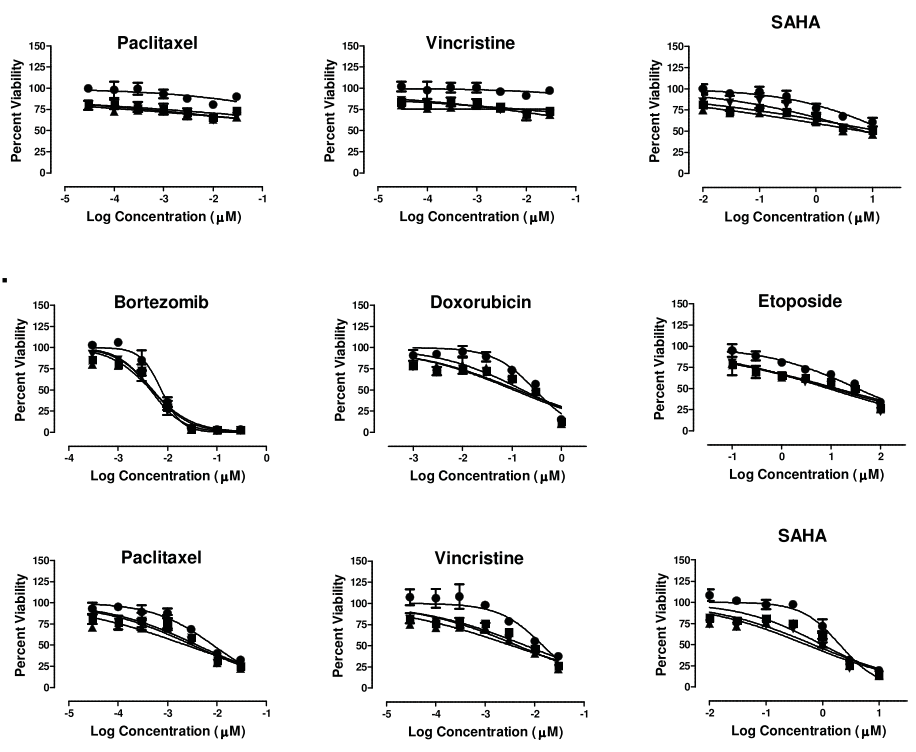

C.
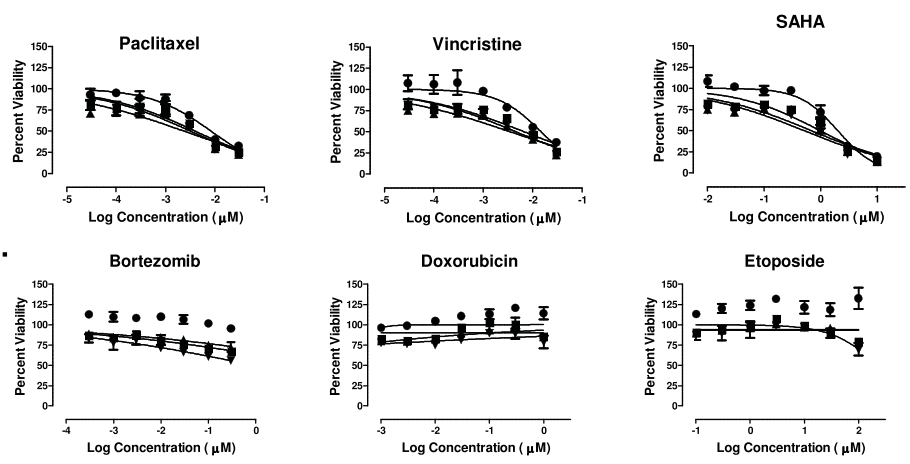

Doxorubicin
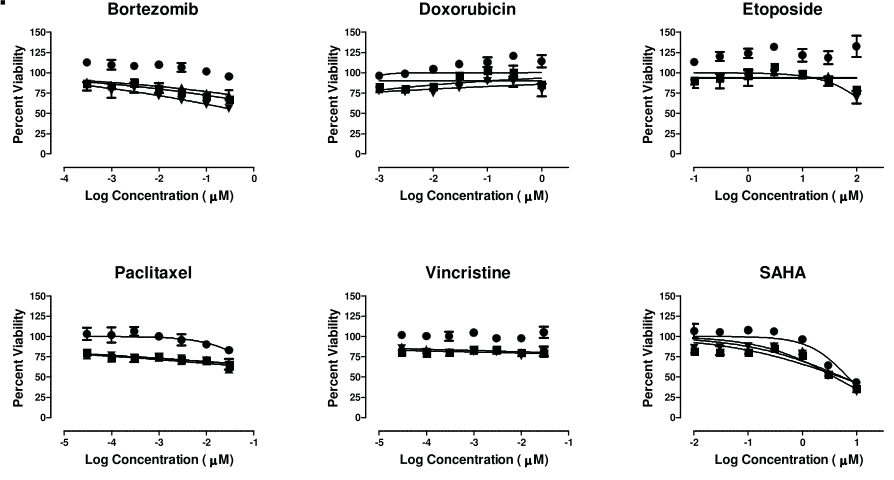

D.
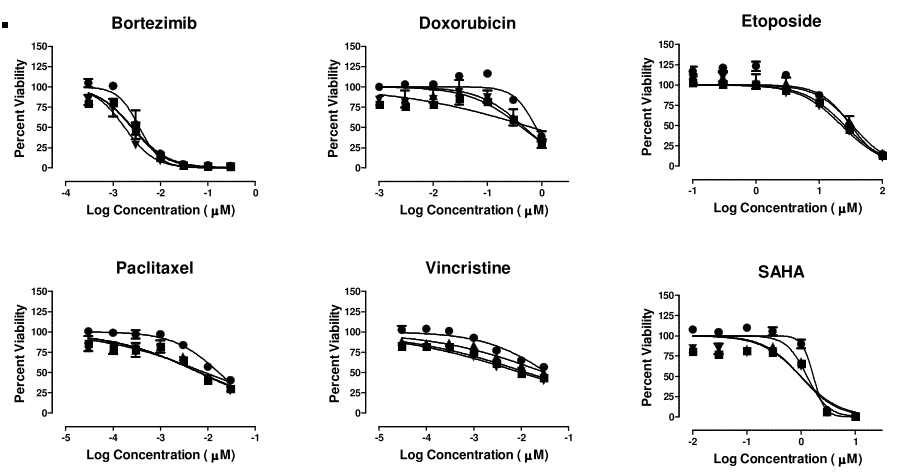

Figure 6 Effect of XIAP depletion on chemosensitivity of HCT-116 and SW620 cells. Cells were electroporated with $1 \mu \mathrm{M}$ control siRNA (con siRNA) or $1 \mu \mathrm{M}$ s1455 XIAP siRNA. HCT-116 and SW-620 were treated with an array of chemotherapeutic agents for 24 hr (A and C, respectively) or $48 \mathrm{hr}(\mathrm{B}$ and D). For the $24 \mathrm{hr}$ exposure, the agents were added $32 \mathrm{hr}$ following electroporation. For the $48 \mathrm{hr}$ exposure, the agents were added $24 \mathrm{hr}$ following electroporation. Untreated cells (black circle); Electroporated cells (black square); 1 MM control siRNA (black triangle) XIAP siRNA (inverted black triangle). 
and 6D; Table 2 Similar results were obtained with these same agents in the PC-3 prostate cancer cell line (Additional File 4) Table 2 To verify efficient knockdown in the HCT-116 and SW-620 cells, XIAP protein levels were determined in parallel cultures of both cell lines at $48 \mathrm{hr}$ post electroporation (knockdown nadir). XIAP mRNA was efficiently targeted in these cells with XIAP protein levels at $13 \%$ and $17 \%$ of the untreated SW-620 and HCT-116 cells, respectively (Additional File 5).

\section{Discussion}

Here we report that transient, siRNA-mediated depletion of XIAP alone does not significantly decrease human tumor cell viability. We interpret the results to mean that XIAP does not have an essential role in growth and

Table 2 Sensitivity of XIAP depleted HCT-116, SW-620 and PC-3 tumor cells to various mechanistically distinct anti-cancer agents.

\begin{tabular}{|c|c|c|c|c|c|}
\hline \multirow[t]{2}{*}{ Drug } & \multirow{2}{*}{$\begin{array}{l}\text { Cell } \\
\text { line }\end{array}$} & \multicolumn{4}{|c|}{$E C_{50}(\mu \mathrm{M})$} \\
\hline & & Untreated & Electroporated & $\begin{array}{c}\text { Control } \\
\text { siRNA }\end{array}$ & $\begin{array}{c}\text { XIAP } \\
\text { siRNA }\end{array}$ \\
\hline Bortezomib & $\begin{array}{c}\text { HCT- } \\
116\end{array}$ & 0.0075 & 0.0050 & 0.0047 & 0.0045 \\
\hline Doxorubicin & $\begin{array}{c}\text { HCT- } \\
116\end{array}$ & 0.29 & 0.13 & 0.16 & 0.11 \\
\hline Etoposide & $\begin{array}{c}\text { HCT- } \\
116\end{array}$ & 34.11 & 12.99 & 10.62 & 8.90 \\
\hline Paclitaxel & $\begin{array}{c}\text { HCT- } \\
116\end{array}$ & 0.0083 & 0.0040 & 0.0024 & 0.0031 \\
\hline SAHA & $\begin{array}{c}\text { HCT- } \\
116\end{array}$ & 2.014 & 0.98 & 0.67 & 0.51 \\
\hline Vincristine & $\begin{array}{c}\text { HCT- } \\
116\end{array}$ & 0.015 & 0.0067 & 0.0035 & 0.0045 \\
\hline Bortezomib & $\begin{array}{l}\text { SW- } \\
620\end{array}$ & 0.0036 & 0.0025 & 0.0025 & 0.0017 \\
\hline Doxorubicin & $\begin{array}{l}\text { SW- } \\
620\end{array}$ & 0.79 & 0.657 & 0.48 & 0.43 \\
\hline Etoposide & $\begin{array}{l}\text { SW- } \\
620\end{array}$ & 31.79 & 25.55 & 33.68 & 22.70 \\
\hline Paclitaxel & $\begin{array}{l}\text { SW- } \\
620\end{array}$ & 0.017 & 0.0067 & 0.0086 & 0.0064 \\
\hline SAHA & $\begin{array}{l}\text { SW- } \\
620\end{array}$ & 1.69 & 0.98 & 1.29 & 0.97 \\
\hline Vincristine & $\begin{array}{l}\text { SW- } \\
620\end{array}$ & 0.035 & 0.013 & 0.031 & 0.0095 \\
\hline Bortezomib & $P C-3$ & 0.01 & 0.0063 & 0.0037 & 0.0041 \\
\hline Doxorubicin & $P C-3$ & 0.15 & 0.073 & 0.038 & 0.038 \\
\hline Etoposide & $P C-3$ & 41.96 & 16.58 & 26.13 & 16.76 \\
\hline Paclitaxel & $P C-3$ & 0.0028 & 0.00090 & 0.00067 & 0.00037 \\
\hline SAHA & $P C-3$ & 1.762 & 0.72 & 0.068 & 0.53 \\
\hline Vincristine & $P C-3$ & 0.0025 & 0.0016 & 0.0016 & 0.0016 \\
\hline
\end{tabular}

Potency $\left(\mathrm{EC}_{50}\right)$ determinations from the dose response curves in Figure 5 (HCT-116 and SW-620) and Additional File 5 (PC3) were determined using non-linear regression and a least squares fit (GraphPad Prism software) survival of tumor cell lines under normal, optimized growth conditions in vitro. This conclusion is consistent with a lack of effect on developmental apoptosis in mice harboring a germ line XIAP mutation and in transformed mouse embryo fibroblasts derived from these XIAP knockout mice [9]. Similar results were obtained with human colorectal cancer cells in which the XIAP locus was deleted via homologous recombination [10]. However, in these studies and others using transient or stable XIAP knockdown, loss of XIAP function sensitized the cells to TRAIL induced apoptosis. Our study is a more expansive survey, and supports the idea that XIAP has a critical role in negatively regulating death receptor mediated apoptosis across a wide array of tumor cell lines derived from diverse tissue types. Surprisingly, similar enhancement of apoptosis was not observed with multiple mechanistically distinct chemotherapeutics or the proteasome inhibitor bortezomib, or the HDAC inhibitor SAHA. All of these agents are thought to induce apoptosis predominantly (but perhaps not exclusively) through the mitochondrial pathway, involving cytochrome $c$ and SMAC release and subsequent activation of caspase- 9 by the apoptosome. Our data strongly suggest that XIAP has a more central role in inhibiting the extrinsic caspase- 8 mediated death pathway than the intrinsic, caspase-9 dependent pathway. One potential explanation for the difference between extrinsic versus intrinsic death inducers is that the latter cause a release of SMAC, an endogenous inhibitor of XIAP. In wild-type cells, the caspase inhibitory activity of XIAP may be neutralized by SMAC following a robust intrinsic death pathway signal, essentially mimicking XIAP depletion. Therefore, no further increase in apoptotic response would be expected in XIAP siRNA treated cells. Support of this hypothesis comes from the elegant studies of the Prehn group, where loss of XIAP function in staurosporine treated HeLa cells did not accelerate substrate cleavage after detection of mitochondrial outer membrane permeabilization [40].

In contrast to our studies, Ras/E1A transformed MEFs derived from XIAP KO mice exhibited an increased sensitivity to the apoptosis inducing effects of etoposide compared to their wild-type counterparts [9]. It is possible that Ras/E1A transformed MEFs are under different apoptotic pressures than the human cancer cells used in our study, resulting in XIAP having a more central role in suppressing intrinsic pathway mediated cell death. Testing the effects of other mechanistically distinct inducers of the intrinsic cell death pathway in Ras/E1A transformed MEFs should help clarify this and determine if the observed effects in MEFs are specific to etoposide.

Yang et al [8] reported that several cell lines, including a subset of those used in this study (BxPC-3, MCF-7, 
and SW-620) exhibited high basal levels of activated caspase- 3 and -8 activity in the absence of other markers of apoptosis. It was argued that these cells were non-apoptotic via a compensatory increase in XIAP expression, which neutralized the caspase activity. Within the same study, over-expression of XIAP-associated factor 1 (XAF-1) in MCF-10A and MDA-MB-231 resulted in an increase in apoptosis. However, the biological activities of XAF-1 are complex and not yet fully elucidated, and thus it is difficult to ascertain whether this increase in cell death is solely mediated by XIAP. The more definitive XIAP knockdown experiments were not performed. If viable tumor cells such as BxPC3 and SW620 do in fact have activated caspases, our data suggests that these "death enzymes" are unlikely to be directly inhibited by XIAP, but rather by some other mechanism. Alternatively, in the context of XIAP knockdown the level of active caspases is still below a threshold necessary to induce cell death. Since $100 \%$ knockdown is never achieved with siRNA, the residual XIAP protein in the siRNA treated cells may be sufficient to inhibit the activated caspases present in these cells.

Several authors have reported that functional p53 is required for XIAP depletion to result in cell death. Tong and colleagues [26] found that the p53 positive MKN-45 gastric carcinoma cell line exhibited an elevated apoptotic rate following XIAP depletion, while the p53 mutant cell line MKN-28 was unaffected. Mohapatra and colleagues [27] reported that XIAP depletion did not result in increased apoptosis in p53 wild type LNCaP or p53 deficient PC-3 prostate cancer cells although over-expression of p53 in both cell lines resulted in apoptosis following XIAP depletion. Our studies included cell lines that harbor wild-type and mutant (loss-of-function) p53, however, there was no obvious correlation between response to XIAP knockdown and p53 status.

Recently, multiple reports indicated that tumor cell death induced by multiple, chemically distinct SMAC mimetics was in fact dependent on the proteasomal degradation of multiple members of the IAP family and subsequent induction of TNF $\alpha$ production and caspase8 mediated death [41]. Treated cells that did not have detectable levels of TNF $\alpha$ did not undergo apoptosis nor did TNF $\alpha$-positive cells that were simultaneously treated with a TNF $\alpha$ blocking antibody. These results lend support to our conclusions from the knockdown experiments that under normal growth conditions in vitro, most tumor cells have not sufficiently engaged an apoptotic pathway such that their survival is dependent on XIAP. Some other death signal is needed (e.g. TNF $\alpha$ production or exogenous TRAIL), which, together with XIAP antagonism results in enhanced apoptosis. One outstanding question is whether the anti-tumor activity of the SMAC mimetics in vivo is also dependent on engagement of the TNF $\alpha$ pathway. It is possible that the associated stresses of in vivo tumor growth (e.g. hypoxia) generate a death signal (activated caspases) that is sufficient to render the tumor cells sensitive to inhibition of XIAP solely via the disruption of the caspase 9/XIAP interaction. In support of this notion, multiple reports have shown that stable shRNA or antisense knockdown of XIAP resulted in decreased tumor cell growth, as subcutaneous xenografts in vivo, but not as culture mono-layers, in vitro $[14,18,32]$. In vivo studies with inducible shRNAs that target XIAP in both nascent and established tumors may help resolve this issue, and should provide further insight for validation of XIAP as a cancer drug target.

\section{Conclusion}

Our work is consistent with others and predicts that agents that simply disrupt the caspase-3/9-XIAP interaction may hold limited therapeutic promise as monotherapy and that their utility will be likely found in the combination setting, in particular with therapies that engage the extrinsic death receptor pathway. Ultimate validation of XIAP as a cancer drug target will come from the clinical development of both the SMAC mimetics and the anti-sense based XIAP cancer therapies, both of which have recently entered Phase I clinical trials.

Additional file 1: Effect of depletion of Polo-like kinase 1 (PLK1) on cell viability. SW-620 cells were electroporated with the concentrations of siRNA indicated. (A and B). After $48 \mathrm{hr}$, cells were lysed, and PLK1 protein levels were detected by Western blot and quantified by LICOR Odyssey imaging. C. Cell viability was measured at $24 \mathrm{hr}$ (unfilled square), $48 \mathrm{hr}$ (light grey square), $72 \mathrm{hr}$ (dark grey square) and $96 \mathrm{hr}$ (black square).

Click here for file

[http://www.biomedcentral.com/content/supplementary/1471-2407-1011-S1.PPT]

Additional file 2: Effect of XIAP depletion on viability and TRAIL sensitivity in SW620 cells using an alternate siRNA. A. Lysates of SW620 and HCT-116 cells were collected $48 \mathrm{hr}$ following electroporation with $1 \mu \mathrm{M}$ control siRNA or XIAP siRNA s1456, and XIAP levels detected by western blot and quantified using LICOR Odyssey imaging (B). Untreated cells (unfilled square), electroporated cells (light grey square), cells electroporated with $1 \mu \mathrm{M}$ control siRNA (dark grey square), or $1 \mu \mathrm{M}$ s1456 XIAP siRNA (black square). Percent XIAP levels are expressed relative to the untreated control. C. Viability of XIAP depleted cells was measured at 24, 48, 72 and 96 hr. Untreated cells (unfilled square), electroporated cells (light grey square), cells electroporated with $1 \mu \mathrm{M}$ control siRNA (dark grey square), or $1 \mu \mathrm{M}$ s1456 XIAP siRNA (black square). D. XIAP depleted cells were exposed to TRAIL 40 hours following electroporation, and viability was measured after $16 \mathrm{hr}$. Percent viability is expressed relative to untreated controls. Untreated cells (black circle), electroporated cells (black square), cells electroporated with $1 \mu \mathrm{M}$ control siRNA (black triangle), or 1 MM s1456 XIAP siRNA (inverted black triangle). Click here for file

[http://www.biomedcentral.com/content/supplementary/1471-2407-1011-S2.PPT]

Additional file 3: Measurement of synergism of XIAP depletion and TRAIL on viability of SW620 cells. Cells were electroporated with 
varying concentrations of siRNA and TRAIL was added $40 \mathrm{hr}$ post electroporation. A and B. Viability was measured using ATPlite $16 \mathrm{hr}$ following addition of TRAIL. Combination index was determined using Compusyn software. A combination index of $<0.1$ is indicative of very strong synergism. (Chou et. al., 2006). 1 MM s1456 XIAP siRNA (black circle). TRAIL (black square) TRAIL and $1 \mu \mathrm{M}$ s1456 XIAP siRNA (black triangle). C. XIAP protein levels at $48 \mathrm{hr}$ post electroporation.

Click here for file

[http://www.biomedcentral.com/content/supplementary/1471-2407-1011-S3.PPT]

Additional file 4: Effect of XIAP depletion on chemosensitivity of PC-3 cells. Cells were electroporated with $1 \mu \mathrm{M}$ control siRNA (con siRNA) or $1 \mu \mathrm{M}$ s 1455 XIAP siRNA. All compounds were added $24 \mathrm{hr}$ following electroporation and incubated for $72 \mathrm{hr}$. Untreated cells (black circle); Electroporated cells (black square); $1 \mu \mathrm{M}$ control siRNA (black triangle) XIAP siRNA (inverted black triangle).

Click here for file

[http://www.biomedcentral.com/content/supplementary/1471-2407-1011-S4.PPT]

Additional file 5: XIAP protein levels in XIAP depleted SW620 and HCT-116 cells. Lysates of SW620 and HCT-116 cells were collected 48 hours following electroporation with $1 \mu \mathrm{M}$ control siRNA or XIAP siRNA s1455, and XIAP protein levels detected by Western blot (A) and quantified using LICOR Odyssey imaging (B). Parallel cultures from the same electroporations were used to determine XIAP depletion on chemosensitivity (Figure 5). Percent XIAP protein levels are expressed relative to the mean of untreated controls.

Click here for file

[http://www.biomedcentral.com/content/supplementary/1471-2407-1011-S5.PPT]

\section{Acknowledgements}

The authors would like to acknowledge the entire Apoptos Team for support and Dr. David Hockenbery (Seattle, WA) for the PATU-I cells.

\section{Author details}

${ }^{1}$ Biology, Apoptos Inc, 10835 Road to the Cure, San Diego, CA 92130, USA. ${ }^{2}$ Aragon Pharmaceuticals, 4215 Sorrento Valley Blvd., Suite 215 San Diego CA 92121, USA.

\section{Authors' contributions}

JS designed and carried out experiments, assembled figures and wrote the paper. FLS contributed with experimental design, analyzed data and helped edit the paper. RP contributed with experimental design and helped edit the paper. JHH contributed with experimental design, analyzed data and wrote the paper. All authors have read and approved the final manuscript.

\section{Competing interests}

FLS and RP are employees and shareholders of Receptos (formerly Apoptos).

$\mathrm{JS}$ and $\mathrm{JHH}$ have no competing interests.

Received: 12 June 2009

Accepted: 12 January 2010 Published: 12 January 2010

\section{References}

1. Hanahan D, Weinberg RA: The hallmarks of cancer. Cell 2000, 100(1):57-70.

2. Salvesen GS, Duckett CS: IAP proteins: blocking the road to death's door. Nat Rev Mol Cell Biol 2002, 3(6):401-10.

3. Wright CW, Duckett CS: Reawakening the cellular death program in neoplasia through the therapeutic blockade of IAP function. J Clin Invest 2005, 115(10):2673-8.

4. Deveraux QL, et al: Cleavage of human inhibitor of apoptosis protein XIAP results in fragments with distinct specificities for caspases. EMBO J 1999, 18(19):5242-5251.

5. Eckelman BP, Salvesen GS, Scott FL: Human inhibitor of apoptosis proteins: why XIAP is the black sheep of the family. EMBO Rep 2006, 7(10):988-94
6. Schimmer AD, et al: Targeting XIAP for the treatment of malignancy. Cell Death Differ 2006, 13(2):179-88.

7. Eckelman BP, Salvesen GS: The human anti-apoptotic proteins, CIAP1 and CIAP2 bind but do not inhibit caspases. J Biol Chem 2006, 281(6):3254-60.

8. Yang $L$, et al: Coexistence of high levels of apoptotic signaling and inhibitor of apoptosis proteins in human tumor cells: implication for cancer specific therapy. Cancer Res 2003, 63(20):6815-24.

9. Rumble JM, Biochem J, et al: Apoptotic sensitivity of murine IAP-deficient cells. 2008, 415(1):21-5

10. Cummins $J M$, et al: X-linked inhibitor of apoptosis protein (XIAP) is a nonredundant modulator of tumor necrosis factor-related apoptosisinducing ligand (TRAIL)-mediated apoptosis in human cancer cells. Cancer Res 2004, 64(9):3006-8.

11. Harlin H, et al: Characterization of XIAP-deficient mice. Mol Cell Biol 2001, 21(10):3604-8.

12. Olayioye MA, et al: XIAP-deficiency leads to delayed lobuloalveolar development in the mammary gland. Cell Death Differ 2005, 12(1):87-90.

13. Hwang $C$, et al: $X$-linked inhibitor of apoptosis deficiency in the TRAMP mouse prostate cancer model. Cell Death Differ 2008, 15(5):831-40.

14. LaCasse EC, et al: Preclinical characterization of AEG35156/GEM 640, a second-generation antisense oligonucleotide targeting X-linked inhibitor of apoptosis. Clin Cancer Res 2006, 12(17):5231-41.

15. Chawla-Sarkar M, et al: Downregulation of Bcl-2, FLIP or IAPs (XIAP and survivin) by siRNAs sensitizes resistant melanoma cells to Apo2L/TRAILinduced apoptosis. Cell Death Differ 2004, 11(8):915-23.

16. Fraser $M$, et al: $\mathrm{p} 53$ is a determinant of $X$-linked inhibitor of apoptosis protein/Akt-mediated chemoresistance in human ovarian cancer cells. Cancer Res 2003, 63(21):7081-8.

17. McManus DC, et al: Loss of XIAP protein expression by RNAi and antisense approaches sensitizes cancer cells to functionally diverse chemotherapeutics. Oncogene 2004, 23(49):8105-17.

18. Desplanques $\mathrm{G}$, et al: Impact of XIAP protein levels on the survival of myeloma cells. Haematologica 2009, 94(1):87-93.

19. Hu P, et al: Critical role of endogenous Akt/IAPs and MEK1/ERK pathways in counteracting endoplasmic reticulum stress-induced cell death. J Biol Chem 2004, 279(47):49420-9.

20. Zhang Y, et al: Transfer of siRNA against XIAP induces apoptosis and reduces tumor cells growth potential in human breast cancer in vitro and in vivo. Breast Cancer Res Treat 2006, 96(3):267-77.

21. Lima RT, et al: Specific downregulation of bcl-2 and xIAP by RNAi enhances the effects of chemotherapeutic agents in MCF-7 human breast cancer cells. Cancer Gene Ther 2004, 11(5):309-16.

22. $\mathrm{Hu} Y$, et al: Antisense oligonucleotides targeting XIAP induce apoptosis and enhance chemotherapeutic activity against human lung cancer cells in vitro and in vivo. Clin Cancer Res 2003, 9(7):2826-36.

23. Ndozangue-Touriguine $O$, et al: A mitochondrial block and expression of XIAP lead to resistance to TRAIL-induced apoptosis during progression to metastasis of a colon carcinoma. Oncogene 2008, 27(46):6012-22.

24. Wilkinson $\mathrm{JC}$, et al: Upstream regulatory role for XIAP in receptormediated apoptosis. Mol Cell Biol 2004, 24(16):7003-14.

25. Liu WH, et al: Notch inhibits apoptosis by direct interference with XIAP ubiquitination and degradation. EMBO J 2007, 26(6):1660-9.

26. Tong QS, et al: Downregulation of XIAP expression induces apoptosis and enhances chemotherapeutic sensitivity in human gastric cancer cells. Cancer Gene Ther 2005, 12(5):509-14.

27. Mohapatra S, et al: Accumulation of p53 and reductions in XIAP abundance promote the apoptosis of prostate cancer cells. Cancer Res 2005, 65(17):7717-23

28. Schmidt $M$, et al: Molecular alterations after Polo-like kinase 1 mRNA suppression versus pharmacologic inhibition in cancer cells. Mol Cancer Ther 2006, 5(4):809-17.

29. Spankuch-Schmitt B, et al: Effect of RNA silencing of polo-like kinase-1 (PLK1) on apoptosis and spindle formation in human cancer cells. J Natl Cancer Inst 2002, 94(24):1863-77.

30. Amantana $A$, et al: X-linked inhibitor of apoptosis protein inhibition induces apoptosis and enhances chemotherapy sensitivity in human prostate cancer cells. Mol Cancer Ther 2004, 3(6):699-707.

31. Mizutani $Y$, et al: Overexpression of XIAP expression in renal cell carcinoma predicts a worse prognosis. Int J Oncol 2007, 30(4):919-25. 
32. Vogler M, et al: Targeting XIAP bypasses Bcl-2-mediated resistance to TRAIL and cooperates with TRAIL to suppress pancreatic cancer growth in vitro and in vivo. Cancer Res 2008, 68(19):7956-65.

33. Ashkenazi A, Herbst RS: To kill a tumor cell: the potential of proapoptotic receptor agonists. J Clin Invest 2008, 118(6):1979-90.

34. Wagner KW, et al: Death-receptor O-glycosylation controls tumor-cell sensitivity to the proapoptotic ligand Apo2L/TRAlL. Nat Med 2007, 13(9):1070-7.

35. Chou TC: Theoretical basis, experimental design, and computerized simulation of synergism and antagonism in drug combination studies. Pharmacol Rev 2006, 58(3):621-81.

36. Letai AG: Diagnosing and exploiting cancer's addiction to blocks in apoptosis. Nat Rev Cancer 2008, 8(2):121-32.

37. Kutuk $\mathrm{O}$, Letai $\mathrm{A}$ : Alteration of the mitochondrial apoptotic pathway is key to acquired paclitaxel resistance and can be reversed by ABT-737. Cancer Res 2008, 68(19):7985-94.

38. Perez-Galan $P$, et al: The proteasome inhibitor bortezomib induces apoptosis in mantle-cell lymphoma through generation of ROS and Noxa activation independent of p53 status. Blood 2006, 107(1):257-64.

39. Marks $P A$, Jiang $X$ : Histone deacetylase inhibitors in programmed cell death and cancer therapy. Cell Cycle 2005, 4(4):549-51.

40. Rehm M, et al: Systems analysis of effector caspase activation and its control by X-linked inhibitor of apoptosis protein. Embo J 2006, 25(18):4338-49.

41. Lin SC, Wu H, Tschopp J: Smac mimetics and TNFalpha: a dangerous liaison?. Cell 2007, 131(4):655-8.

42. Ahmed MM, et al: EGR-1 induction is required for maximal radiosensitivity in A375-C6 melanoma cells. J Biol Chem 1996, 271(46):29231-7.

43. Redston MS, et al: p53 mutations in pancreatic carcinoma and evidence of common involvement of homocopolymer tracts in DNA microdeletions. Cancer Res 1994, 54(11):3025-33.

44. O'Connor PM, et al: Characterization of the p53 tumor suppressor pathway in cell lines of the National Cancer Institute anticancer drug screen and correlations with the growth-inhibitory potency of 123 anticancer agents. Cancer Res 1997, 57(19):4285-300.

45. Mashima T, et al: p53-defective tumors with a functional apoptosomemediated pathway: a new therapeutic target. J Natl Cancer Inst 2005, 97(10):765-77.

46. Kawasaki T, et al: Abrogation of apoptosis induced by DNA-damaging agents in human bladder-cancer cell lines with p21/WAF1/CIP1 and/or p53 gene alterations. Int J Cancer 1996, 68(4):501-5.

\section{Pre-publication history}

The pre-publication history for this paper can be accessed here:http://www. biomedcentral.com/1471-2407/10/11/prepub

doi:10.1186/1471-2407-10-11

Cite this article as: Sensintaffar et al:: XIAP is not required for human tumor cell survival in the absence of an exogenous death signal. BMC Cancer 2010 10:11.

\section{Submit your next manuscript to BioMed Central and take full advantage of:}

- Convenient online submission

- Thorough peer review

- No space constraints or color figure charges

- Immediate publication on acceptance

- Inclusion in PubMed, CAS, Scopus and Google Scholar

- Research which is freely available for redistribution

Submit your manuscript at www.biomedcentral.com/submit 